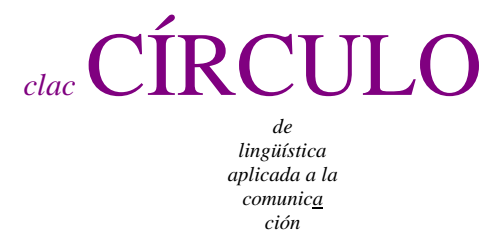

$56 / 2013$

\title{
LA ENTRADA LÉXICA EN EL DISCURSO LEXICOGRÁFICO DIGITAL
}

\author{
Concepción Maldonado González \\ Universidad Complutense de Madrid \\ mariaconcepcionmaldonado en pdi ucm es
}

\section{Resumen}

A partir de soluciones prácticas, intentaremos mostrar cómo el procedimiento de la consulta de la entrada léxica está viviendo cambio de paradigma debido a las muy distintas necesidades de los usuarios según se enfrenten a la búsqueda de información en un diccionario en papel o en el discurso lexicográfico digital.

Palabras clave: diccionario en papel, entrada léxica, discurso lexicográfico digital, usuarios de diccionarios.

\author{
Abstract \\ Lexical entries in digital lexicographical discourse. Dealing with practical solutions, we \\ will try to show how the process of looking up a lexical entry is undergoing a change in \\ paradigms due to the very different needs of dictionary users, depending on whether \\ they are looking for information in paper or in digital lexicographical discourse. \\ Key words: dictionary users, digital lexicographical discourse, lexical entry, paper \\ dictionaries. \\ Maldonado, Concepción. 2013. \\ La entrada léxica en el discurso lexicográfico digital. \\ Círculo de Lingüística Aplicada a la Comunicación 56, 26-52. \\ http://www.ucm.es/info/circulo/no56/lopez.pdf \\ http://revistas.ucm.es/index.php/CLAC \\ DOI: http://dx.doi.org/10.5209/rev_CLAC.2013.v56.43865 \\ (C)2013 Concepción Maldonado González \\ Círculo de Lingüística Aplicada a la Comunicación (clac) \\ Universidad Complutense de Madrid. ISSN 1576-4737. http://www.ucm.es/info/circulo
}


Índice

Resumen 26

Abstract 26

1. Planteamiento 27

2. Los diccionarios: ¿Cambio de formato o cambio de paradigma? 27

3. ¿Qué era antes un diccionario? 32

4. ¿Qué es hoy un diccionario? 41

5. Conclusión 51

Bibliografía 51

\section{Planteamiento}

Este artículo no pretende sino ser una reflexión en voz alta sobre ese cambio en el tratamiento de la información que los usuarios nos vienen demandando a los lexicógrafos en estos últimos años. Nuestro objetivo, pues, no es sino exponer una experiencia de trabajo real y analizar sus resultados desde un enfoque práctico y a partir de propuestas lexicográficas concretas. No plantearemos marcos teóricos complejos en los que encuadrar cada solución práctica sino que, a partir de estas últimas, intentaremos mostrar cómo el procedimiento de la consulta está viviendo un cambio de paradigma debido a las muy distintas necesidades de los usuarios según se enfrenten a la búsqueda de información en un diccionario en papel o en digital.

2. Los diccionarios: ¿Cambio de formato o cambio de paradigma?

El trabajo de los lexicógrafos (o hacedores de diccionarios, que lo mismo somos) ha cambiado mucho en los últimos años: los diccionarios han dejado de ser publicaciones más o menos voluminosas con listados de términos ordenados alfabéticamente (Fig. 1)para pasar aconvertirse en un conjunto de programas y sitios web que "corren" por debajo de nuestros ordenadores y que nos permiten obtener la misma información (al 
menos, la misma)que antes obteníamos viajando entre la A y la Z (véase Fig. 2 en la página siguiente). Donde antes encontrábamos ininteligibles signos de transcripción fonética ahora podemos oír cómo se pronuncia una palabra, incluso con distintos acentos regionales (Fig. 3); y frente a las tradicionales barrerasde entrada de consulta (conocer el orden alfabético, y saber con qué criterios morfológicos se establecía cuál era el lema para cada categoría verbal: infinitivo para los verbos, masculino singular para adjetivos y sustantivos, por ejemplo) ahora es habitual poder acceder a una palabra desde cualquiera de sus formas (amaldecir podemos llegar desde maldije, como a niño podemos llegar desde niñitas; véase Fig. 4 en la página siguiente).

Fig. 1 -Varios diccionarios generales. Abierta, la vigésima primera edición del DRAE (1992).

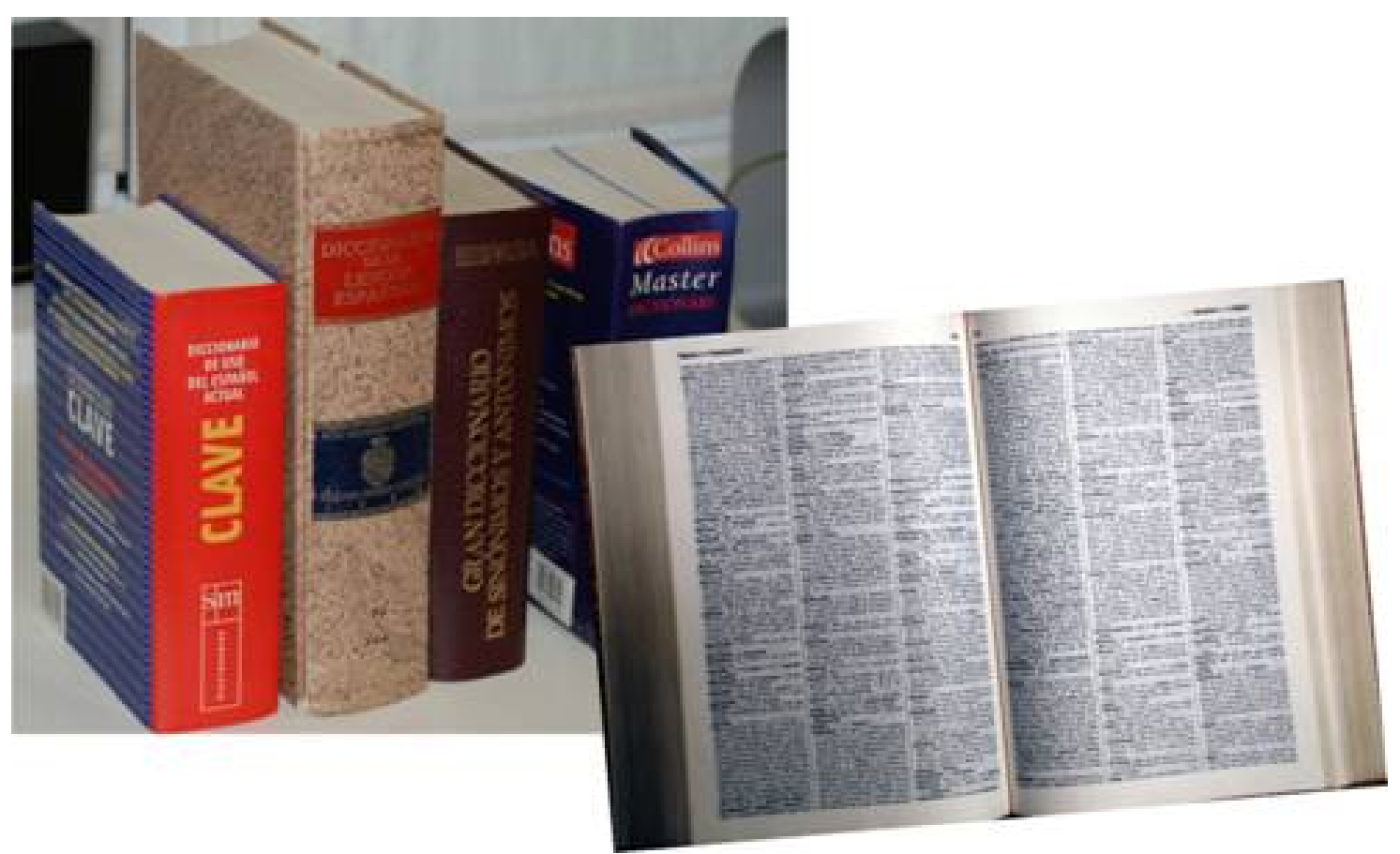


Fig. 2 -Con el botón derecho, en Word 2003 se accede a un pequeño conjunto de sinónimos de la que se considera la acepción más frecuente (Cfr. Millán, 2011).

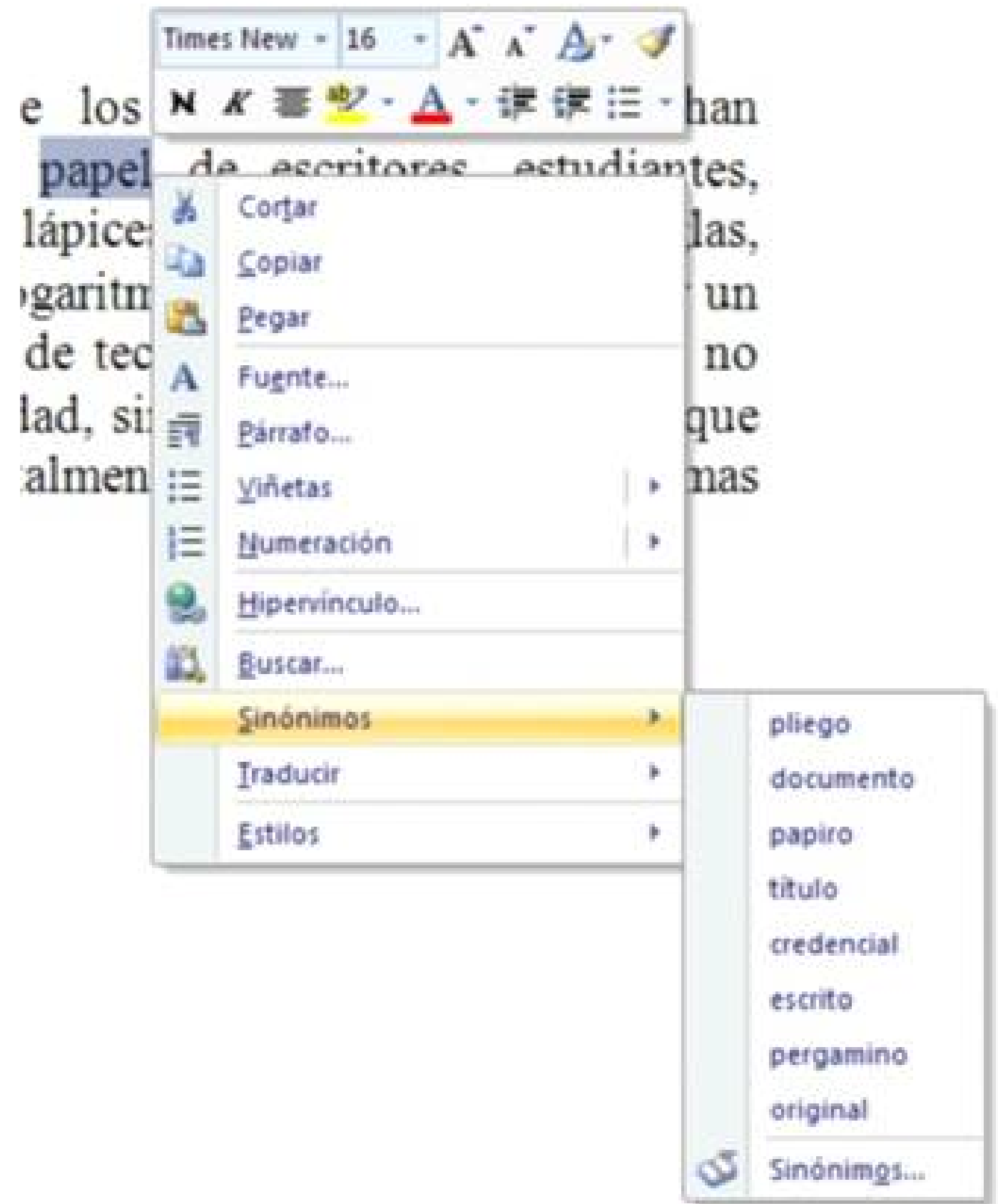


Fig. 3 -Transcripción fonética de blood en el Diccionario Cambridge Pocket(2008), y audio en la web de My World Learner's Dictionary (2012).

blow conoland/ adj, $n$ [c] srubio,bia: She has ,ed her hair blonde. Se ha puesto rubia; ogüero,ra AMER.

'blood/blıd/ [0] ssangre: $a$ blood test - un analisis de sangre; $a$ blood donor un donante de sangre; blood group - grupo sanguíneo; blood pressure - tensión sanguínea a Provi la doble vocal se pronuncia como la $u$ en el lermino ingless sun

bloodbath UK: /blıd.ba: $\theta /$ US: /-bx $\theta / n$ [ No PL] -baño de sangre -carnicería

- 'nod clot $n[c]$ ecoágulo de sangre

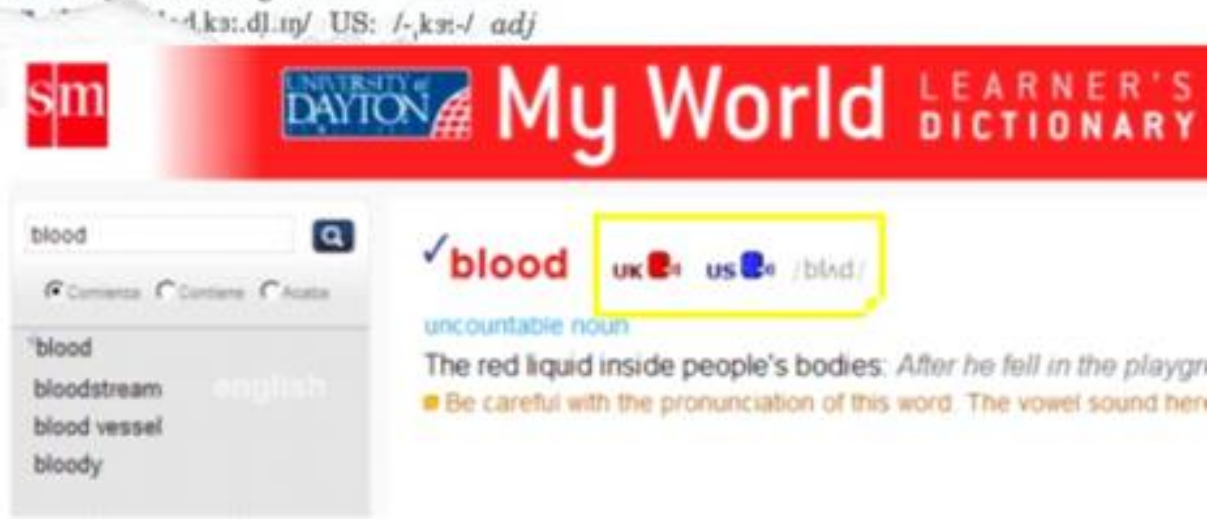

Fig. 4 -Al escribir maldije en la caja de búsqueda de Clave, se llega a maldecir.

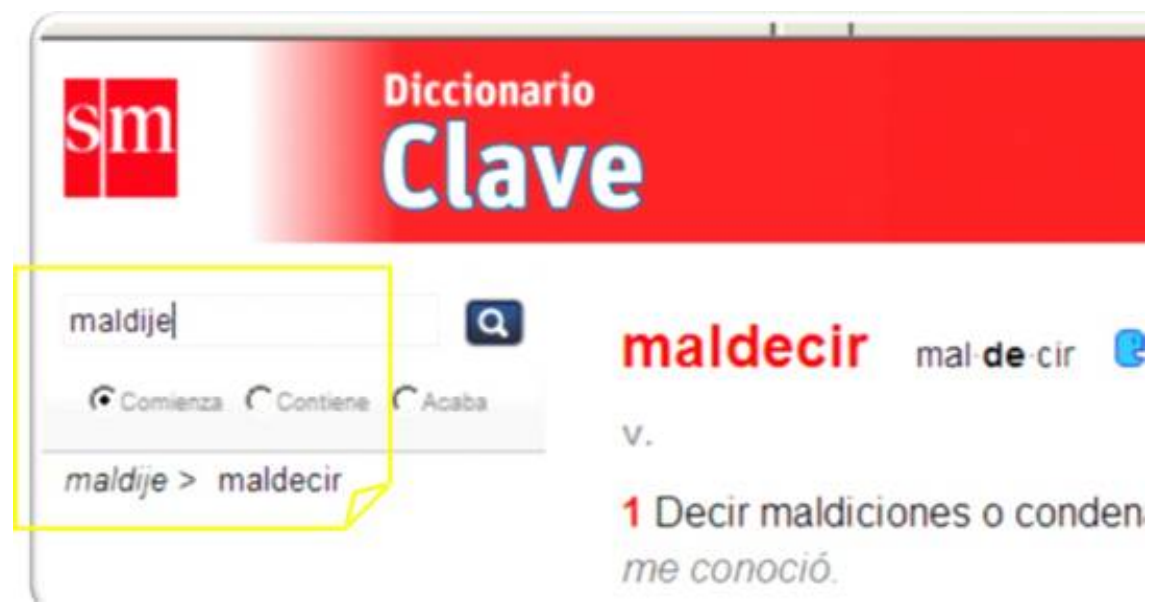


Este cambio de formato (del papel a lo digital) ha sido tan claro y está siendo tan apoyado por los usuarios, que ven resueltas sus necesidades de una forma mucho más rápida y efectiva, que se habla incluso de un cambio de paradigma. Sin entrar aquí en discusiones terminológicas sobre si la revolución científica que estamos viviendo en la lexicografía es consecuencia de un cambio conceptual (Kuhn, 1971) o de un cambio de herramienta (Dysson, 1997: cf. Rojo, 2007); y sin intentar determinar si la magnitud del cambio es equivalente o no a la que supuso para la literatura el paso de la oralidad a la escritura, lo que sí parece claro es que el punto de inflexión lo ha producido la ruptura de la linealidad. Ha sido el hipertexto, ese sistema informático que permite acceder a toda la información escrita contenida en el ordenador y manipularla según se necesite, esa posibilidad de saltar de palabra en palabra sin reparar en su búsqueda alfabética bajo una forma canónica, lo que ha permitido no ya una nueva forma de trabajo lexicográfico, sino también, y sobre todo, una nueva forma de buscar y obtener la información (Fig. 5).

Fig. 5 -Enlaces por hipertexto en los diccionarios on line de http://www.smdiccionarios.com

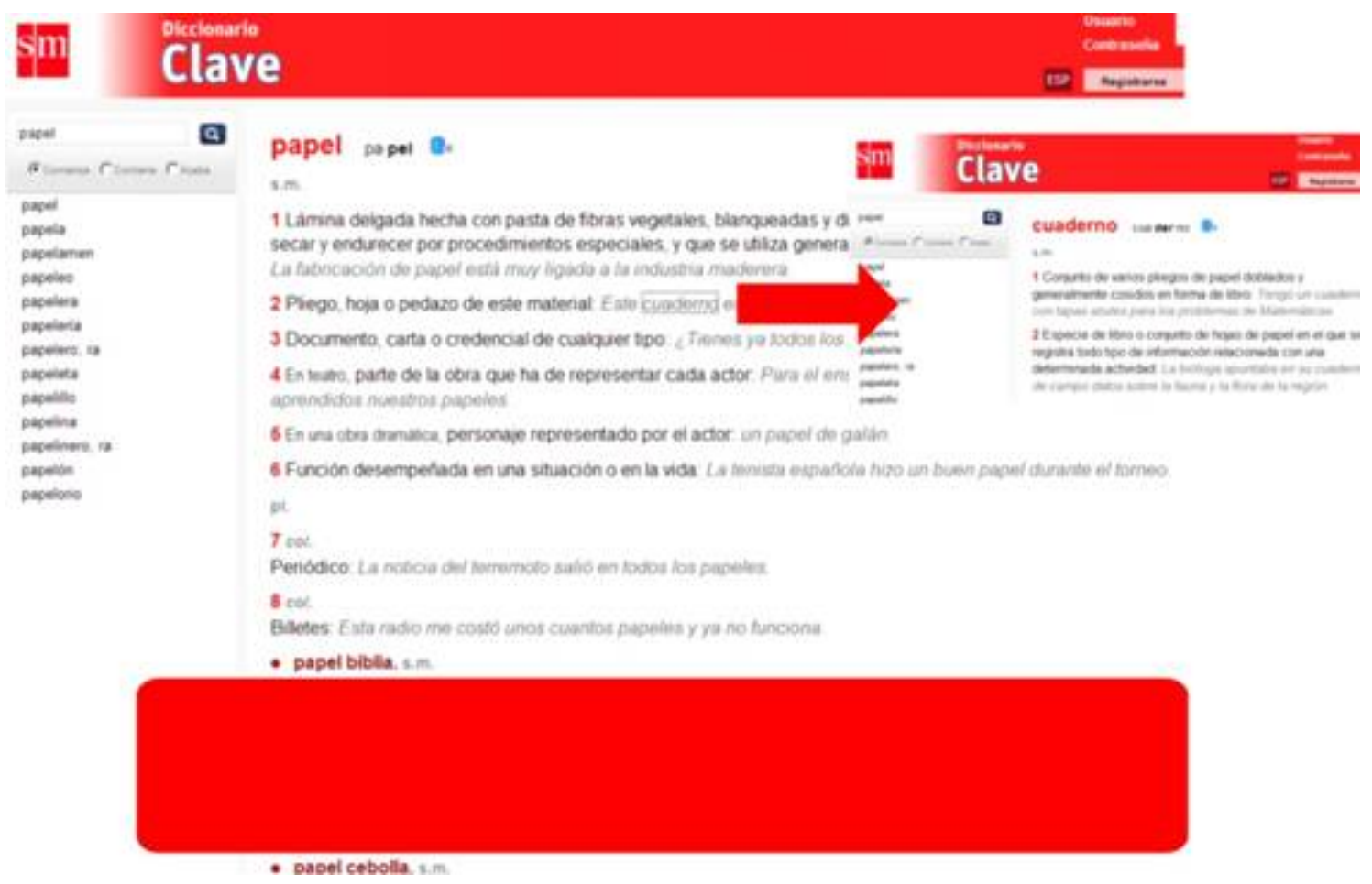


En palabras de Guillermo Rojo (2007):

\begin{abstract}
"Un diccionario en papel se organiza con un único criterio o bien con una serie de criterios jerarquizados, mientras que el formato electrónico permite, por su propia esencia, acceder por vías diferentes a la misma información. En cierto modo, el formato electrónico permite tener el equivalente de varios diccionarios tradicionales en un único soporte ${ }^{1}$, lo cual, unido a su comodidad de transporte y facilidad de manejo explica el enorme éxito que ha tenido este producto.
\end{abstract}

3. ¿Qué era antes un diccionario?

Los diccionarios eran (muchos lo son aún) unas publicaciones en papel que incluían un listado de términos ordenados alfabéticamente y cuya finalidad era la consulta de un dato puntual (cf. Millán, 2011), bien sobre el mundo que habitamos (los diccionarios enciclopédicos; véase la Fig. 6 en la página siguiente), o bien sobre los términos léxicos en sí mismos: su significado (los diccionarios de la lengua) (Fig. 7), su origen (los etimológicos) (Fig. 8), la correcta forma de escribirlos (diccionarios ortográficos; Fig. 9), su sustitución por palabras con el mismo sentido (los de sinónimos; Fig. 10),su combinación con otras palabras (los combinatorios; Fig. 11), su integración en una frase (los de construcción y régimen), su equivalente en otro idioma (los bilingües; Fig. 12 y Fig. 13), su coincidencia con otras palabras en los sonidos finales que constituyen la rima (diccionarios inversos; Fig. 14), etc.

\footnotetext{
${ }^{1}$ El subrayado es nuestro.
} 
Fig. 6 -Diccionario de ESO y Bachillerato (4ª ed.: Madrid, SM, 2012).

Fig. 7 (dcha.) -Diccionario de ESO y Bachillerato (4 ed.: Madrid, SM, 2012).
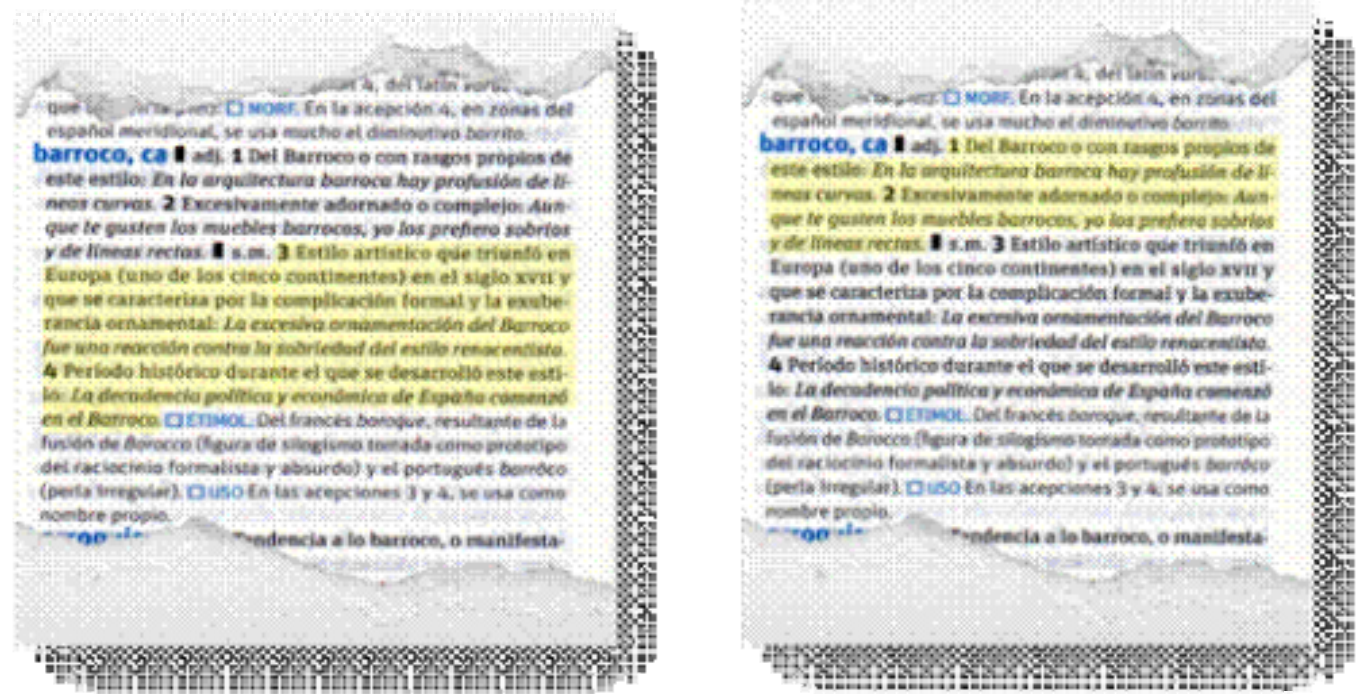

Fig. 8 -Diccionario de ESO y Bachillerato (4 $4^{\text {a }}$ ed.: Madrid, SM, 2012).

Fig. 9 (dcha.) -Diccionario de ESO y Bachillerato (4 ed.: Madrid, SM, 2012).
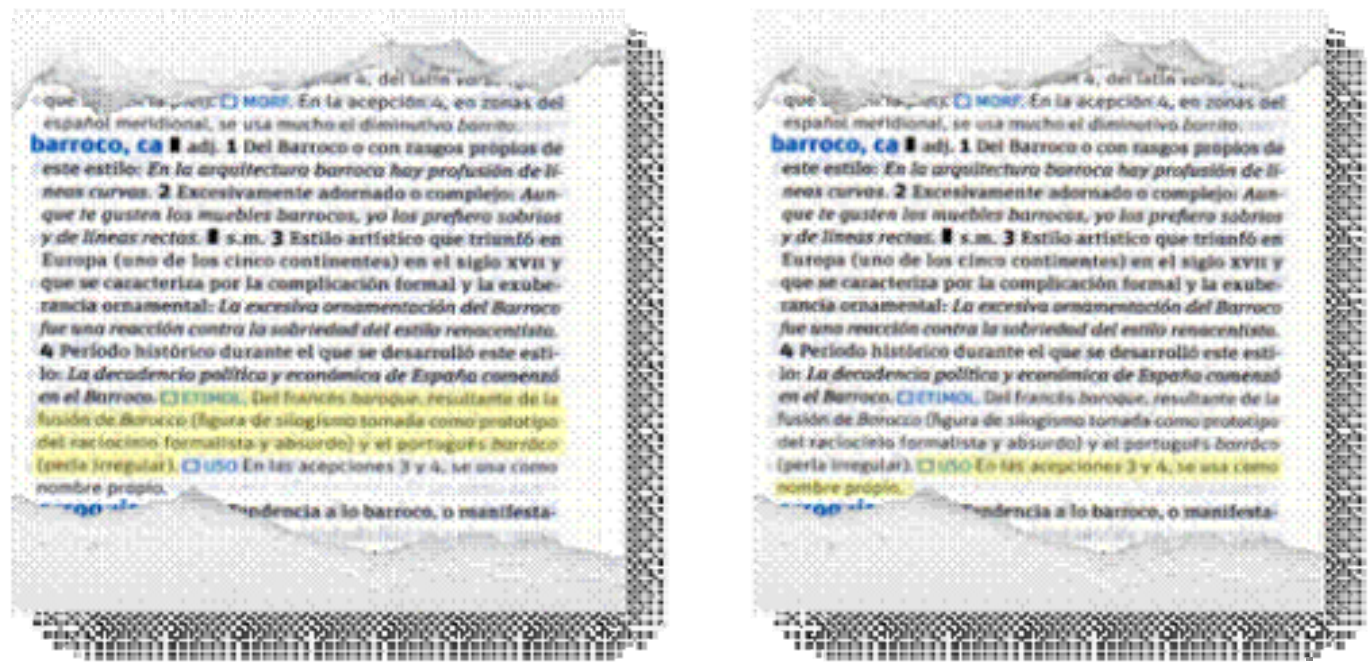
Fig. 10 -Diccionario de sinónimos y antónimos (6ª ed.: Madrid, SM, 2012).

Fig. 11 -Diccionario combinatorio práctico del español actual (Madrid, SM, 2006).

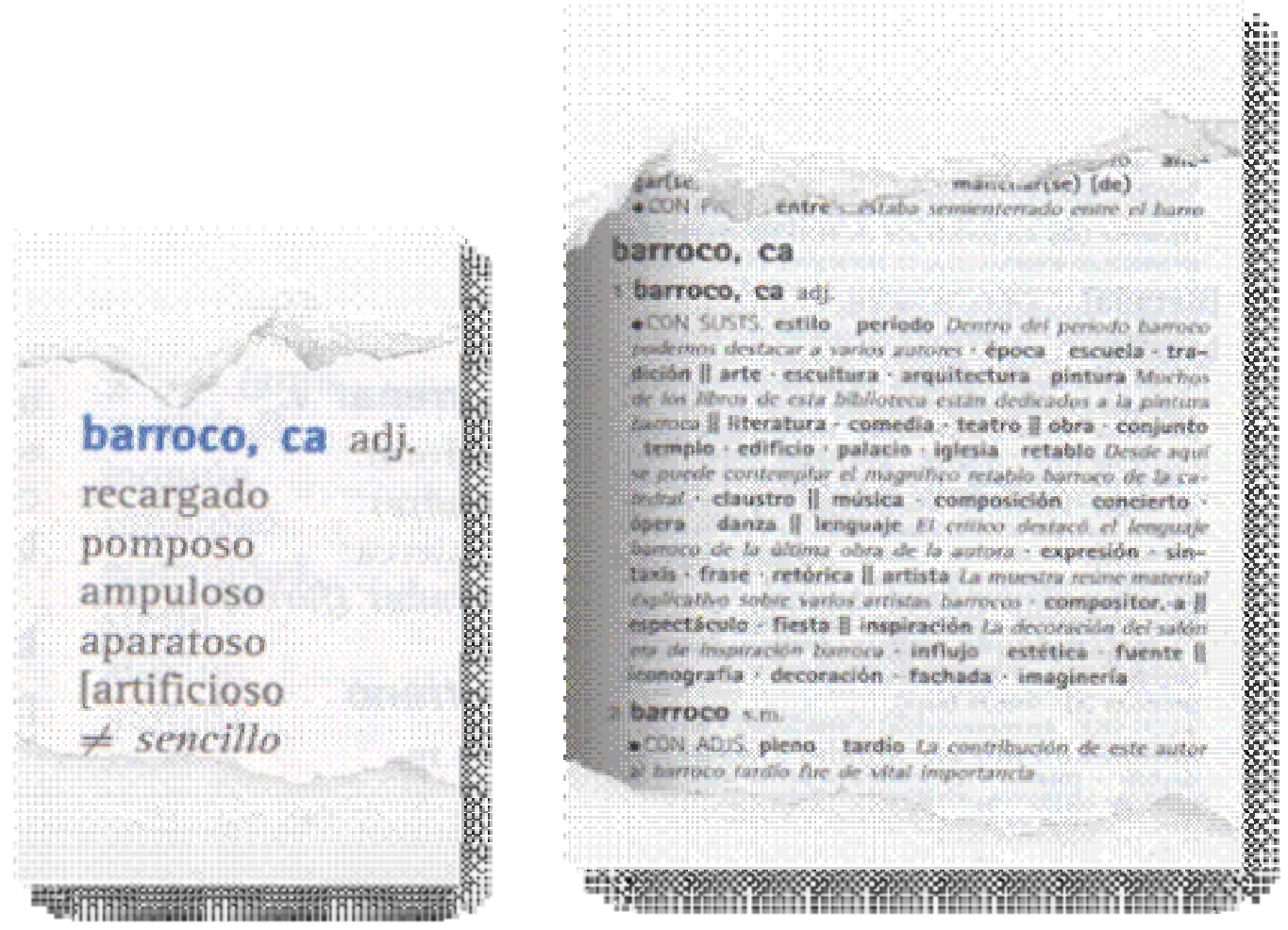

Fig. 12 -Diccionario Cambridge Compact (2008).

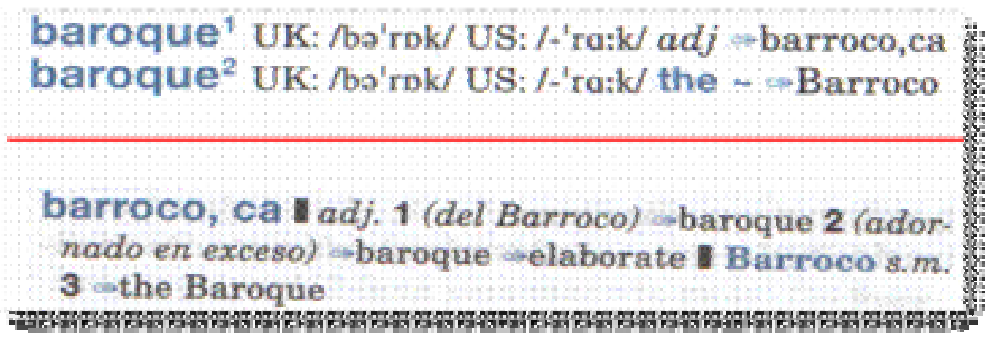

Fig. 13 -Dico (8 ed.: Madrid, SM, 2012).

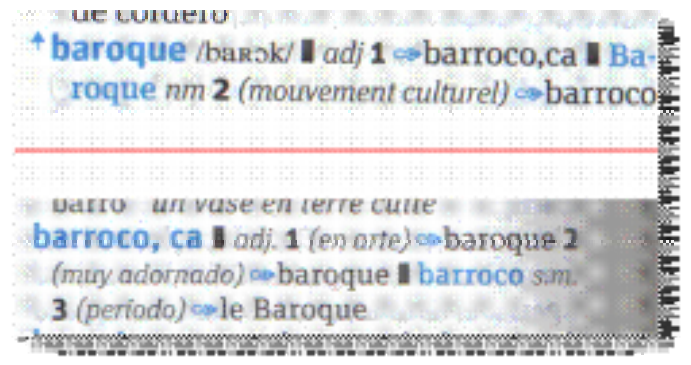


Fig. 14 -En Clave, búsqueda de palabras acabadas en -ción.

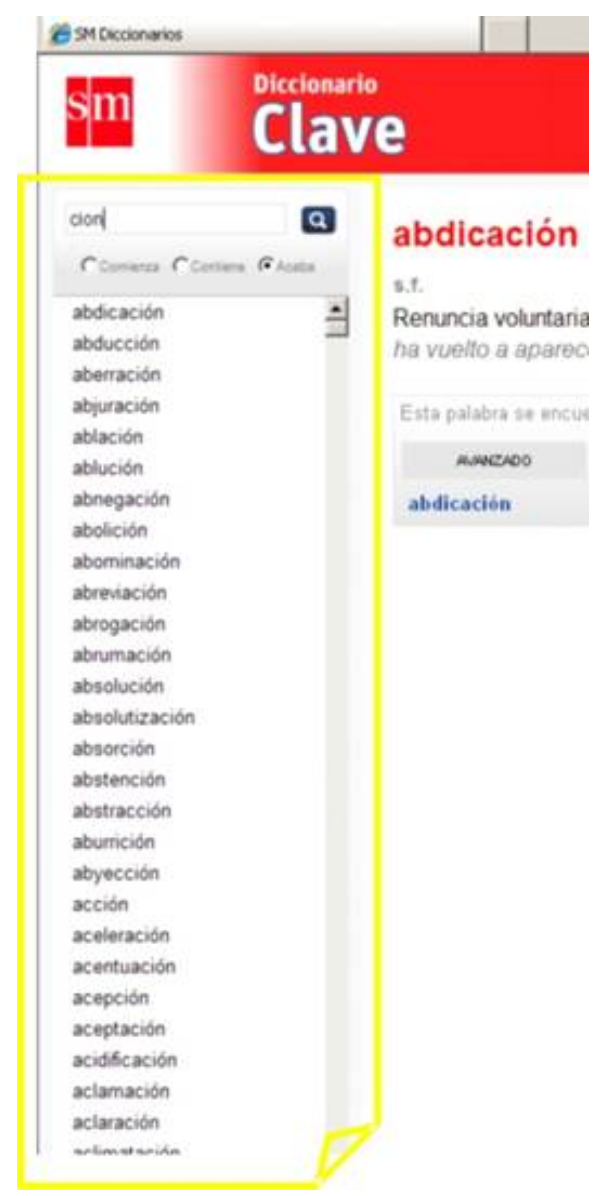

Esta concepción suponía una lectura pormenorizada del dato (no se leía la obra de principio a fin, sino que cada artículo lexicográfico se concebía como una unidad cerrada con valor discursivo en sí misma) ${ }^{2}$. Y los datos estaban relacionados entre sí, pero no integrados (al contrario de lo que ocurría en las monografías o en los manuales; Fig. 15) ${ }^{3}$.

\footnotetext{
${ }^{2}$ Solo así se entiende que obras lexicográficas de gran valor (y de muchos miles de páginas) hayan sido destruidas en su reputación (y descatalogadas, incluso) por la inclusión de un error, algo que pocas veces ha ocurrido en otro tipo de textos de divulgación científica... Fueron sonados la inclusión por error de una foto de una seta venenosa en el apartado de las setas comestibles en la Enciclopedia Larousse a finales del siglo pasado; o, a principios de este siglo XXI, la descatalogación y retirada de las librerías del Diccionario de palabras afines de Fernando Corripio, por lo desfasadas, obsoletas y ofensivas que resultaban todas las entradas relativas al mundo de la homosexualidad, al tratarse de un diccionario que llevaba reimprimiéndose, que no reeditándose, sin cambio alguno, desde el año de su primera edición (1971).

${ }^{3}$ De hecho, en esta concepción de una obra de consulta desde el papel, obras como el Diccionario enciclopédico de las ciencias del lenguaje, de Ducrot y Todorov (1983)supusieron auténticos revulsivos
} 
Fig. 15 -Definición de diccionario dentro del capítulo Componentes de la descripción lingüística (Ducrot, 1983: 67).

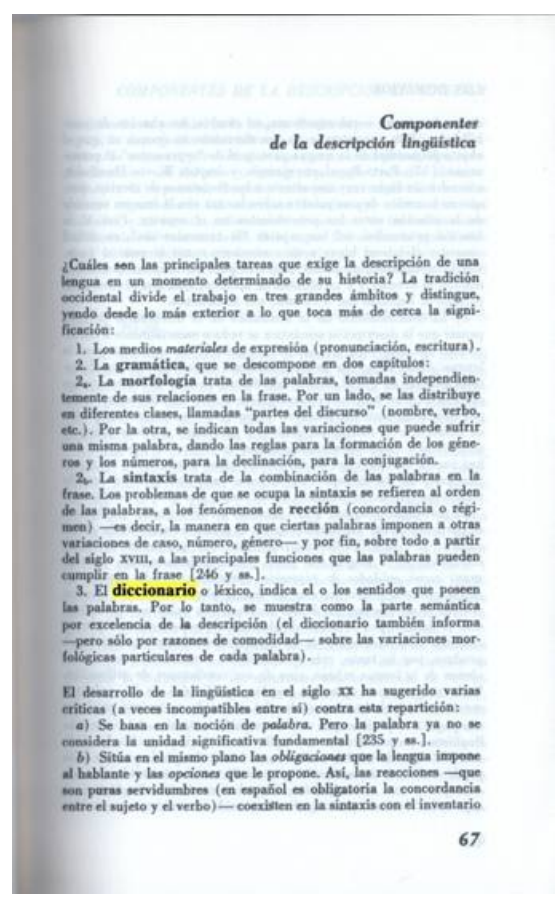

Los diccionarios, pues, eran recopilaciones alfabéticas de elementosléxicos de una lengua (o de dos, o de tres...), en los que se intentaba dar la mayor información posible en el menor espacio posible.

Y esta limitación de espacio (lo primero que sabemos al definir el proyecto editorial de un diccionario es el número de páginas y su formato, porque esto marca el coste de fabricación y define, por tanto, el número de ejemplares que deben venderse para que el proyecto resulte rentable); esta necesidad, en fin, de "gastar" el menor número posible de matrices, ha definido durante siglos las peculiares características discursivas de la entrada léxica:

en la ordenación de la información, ya que el acceso a los términos precisos se hacía desde un índice temático que remitía al párrafo en el que dicho término estaba definido dentro del capítulo teórico en que se enmarcaba. La definición de los conceptos, por tanto, no estaba organizada según una lista de palabras sino mediante una división conceptual del campo estudiado. 
a) Abreviaturas y acortamientos gráficos (véase la Fig. 16 en la página siguiente):

- Abreviaturas (tanto en la descripción de la categoría gramatical de cada término, como en el cuerpo del discurso). ${ }^{4}$

- Numeración ausente en las acepciones (al menos, en la primera) o sustitución de los números por la doble barra, que ocupa mucho menos espacio.

- Presentación del femenino en el lema (solo las letras finales) ${ }^{5}$.

- Sustitución del lema por la virgulilla en las locuciones

Fig. 16 -Vigésima primera edición del DRAE (1992).

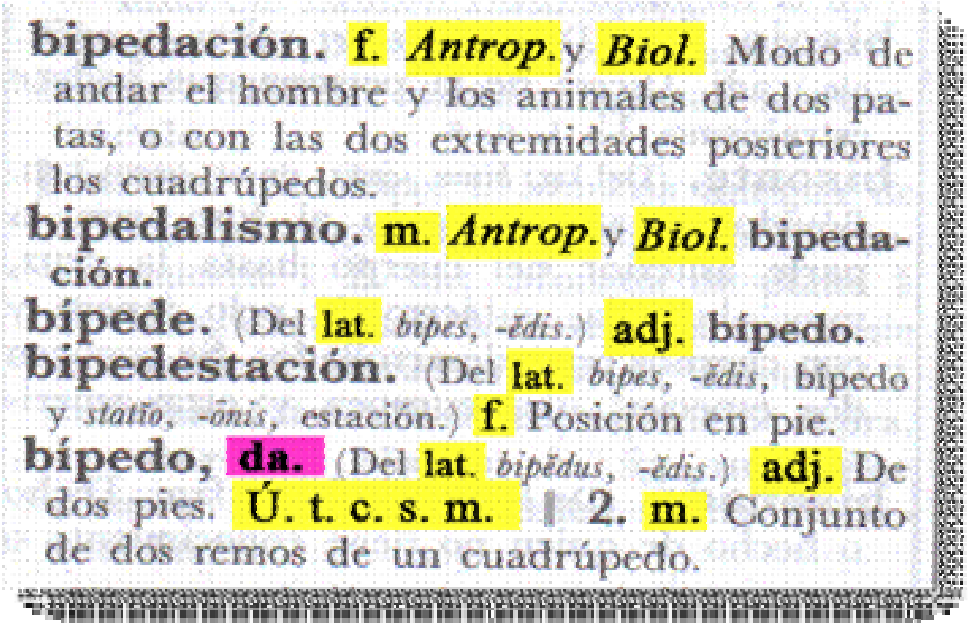

b) Fórmulas de redacción fijas y basadas en la remisión conceptual, sobre todo, en palabras dela misma familia morfológica: los sustantivos en -ción o en mientose definen como Acción y efecto de...; los sustantivos en -dad, como Calidad de...; los adjetivos en -ble,como Que puede ser...) (Fig. 17).

\footnotetext{
${ }^{4}$ En un diccionario como Clave, por ejemplo, con un lemario que ocupa 1947 páginas sobre las 2080 páginas de la obra en su totalidad, el uso de unas 90 abreviaturas ha permitido ahorrar 1.240.000 matrices, lo que supone un ahorro final en papel de250 páginas.

${ }^{5}$ Esto lleva en ocasiones a malas interpretaciones sobre la ortografía de una palabra en femenino, algo que resulta patente cuando los diccionarios son utilizados en el aprendizaje de segundas lenguas: ¿qué pasa con la tilde en chupona? (chupón, na), ¿cuál es el femenino de cargador (cargador, ra): cargadora o cargadorra?
} 
Fig. 17 -Vigésima primera edición del DRAE (1992).

$$
\text { conducible. adj. Que puede ser conducido }
$$

bondad. (Del lat. bonitas, -âtis.) f. Calidad de bueno. \| 2. Natural inclinación a hacer el bien. II 3. Blandura y apacibilidad de genio.

c) Abundancia de remisiones (Fig. 18).

Fig. 18 -Vigésima primera edición del DRAE (1992).

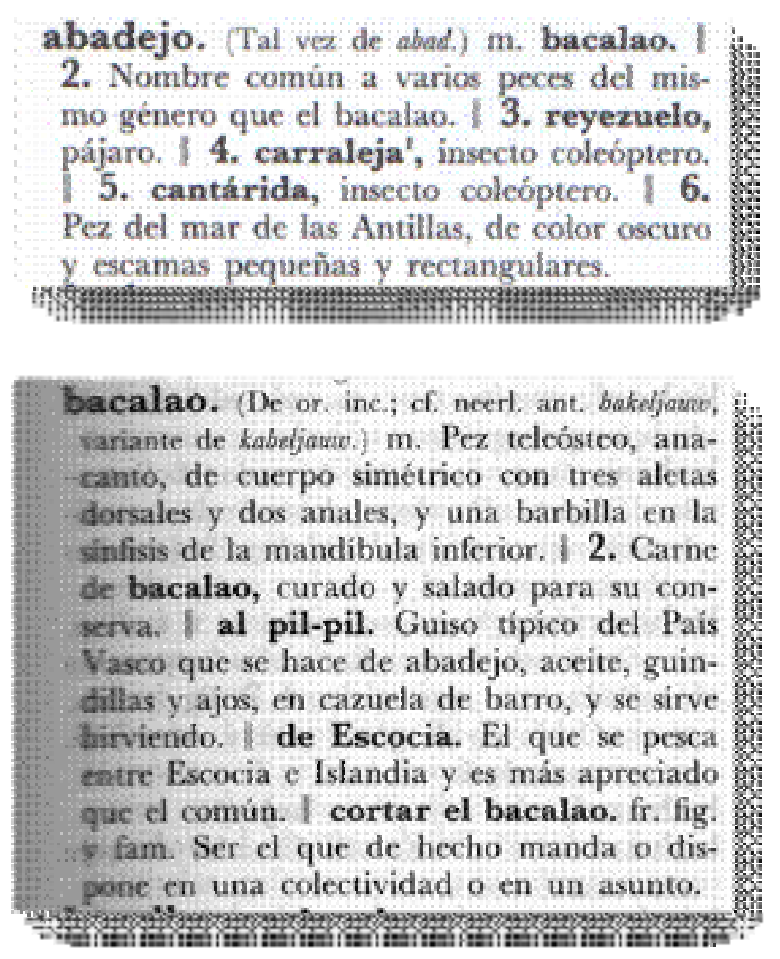

- Además, el propio lemario registraba una forma canónica única para todas las formas y variantes de una palabra; solo en el caso de los diccionarios específicamente pensados para el aprendizaje de segundas lenguas se incluían las formas morfológicas irregulares más difíciles de reconocer como pertenecientes a una familia y se listaban alfabéticamente en el lemario; Fig. 19). 
Fig. 19 -Dico (8a ed.: Madrid, SM, 2012).

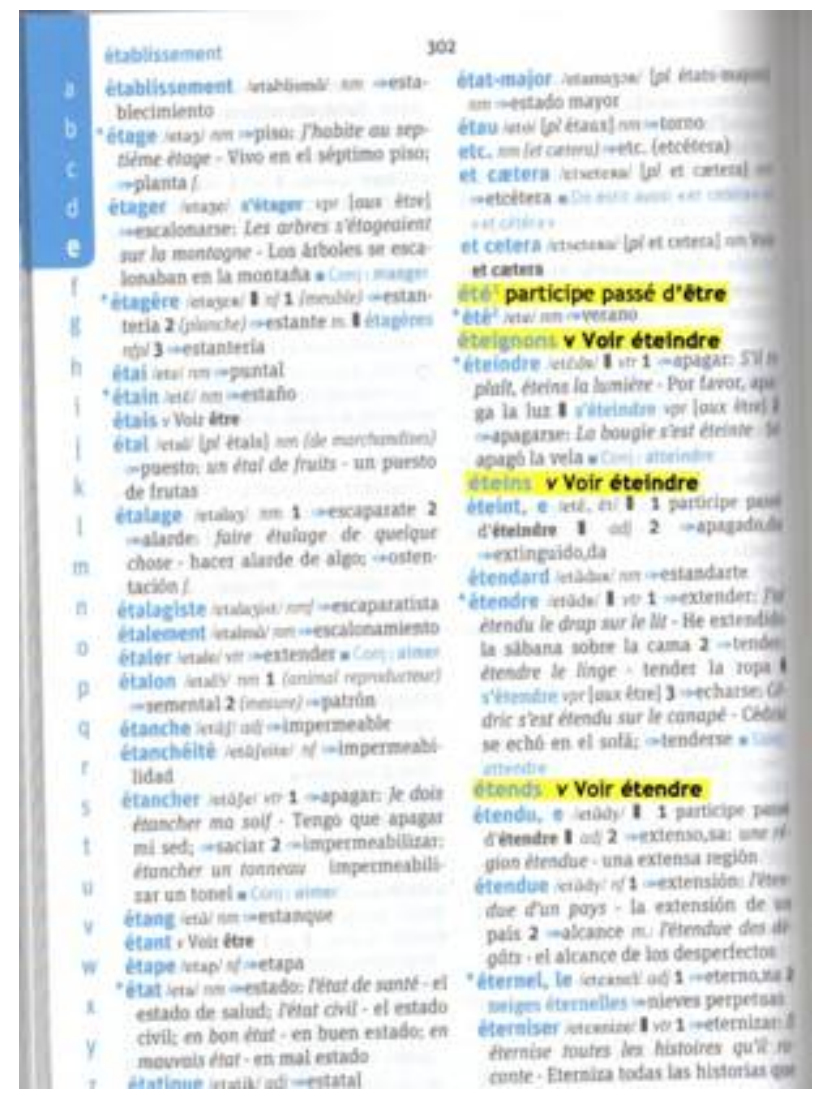

- De hecho, las palabras compuestas o derivadas (sobre todo, las derivadas) cuyo significado era fácilmente deducible a partir del significado de su raíz y de los morfemas derivativos, no se incluían en el lemario (sería el caso de los diminutivos, despectivos, los adverbios en -mente, etc. $)^{6}$

d) En el aspecto físico de la obra, son muchas las características de diseño, maquetación y fabricación que los usuarios asociamos ya indisolublemente al discurso lexicográfico:

- Composicióndel texto a dos o más columnas.

- Cuerpo de letra pequeño

\footnotetext{
${ }^{6} \mathrm{El}$ único adverbio en-mente que debería figurar por derecho propio en cualquier diccionario de español (y muy en especial, si los destinatarios son personas que aprenden español como segunda lengua), es seguramente, un adverbioque, pese a lo que la etimología pudiera indicar, no significa 'de forma segura' sino 'probablemente, ‘a lo mejor'...
} 
- Selección de aquellas fuentes tipográficas que, por tener un ojo mayor, admiten cuerpos de letra pequeños sin perder legibilidad.

- Apéndices comunes a los que se remite desde distintas entradas del diccionario.

- Los anexos, tan característicos de las grandes obras de consulta (Fig. 20). De hecho, la actualización de la información en las tradicionales enciclopedias se realizaba mediante la edición anual de anexos que, otra vez en orden alfabético, listaban en un volumen anuallas enmiendas o añadidos rastreados como necesarios en los volúmenes anteriormente editados. ¿Qué “aberración” suponía esto en la aplicación del procedimiento de la consulta? Pues que la consulta exhaustiva de unaobra de varios tomos no finalizaba nunca con la mera consulta del tomo de la letra en cuestión, sino que dicha lectura debía completarse con la revisión de la información recogida en esa letra en cada anexo existente, ya que al reimprimirse (que no reeditarse) la obra original no se avisaba de cuáles eran los artículos enmendados.

Fig. 20 -Encyclopedia Britannica (32 tomos)

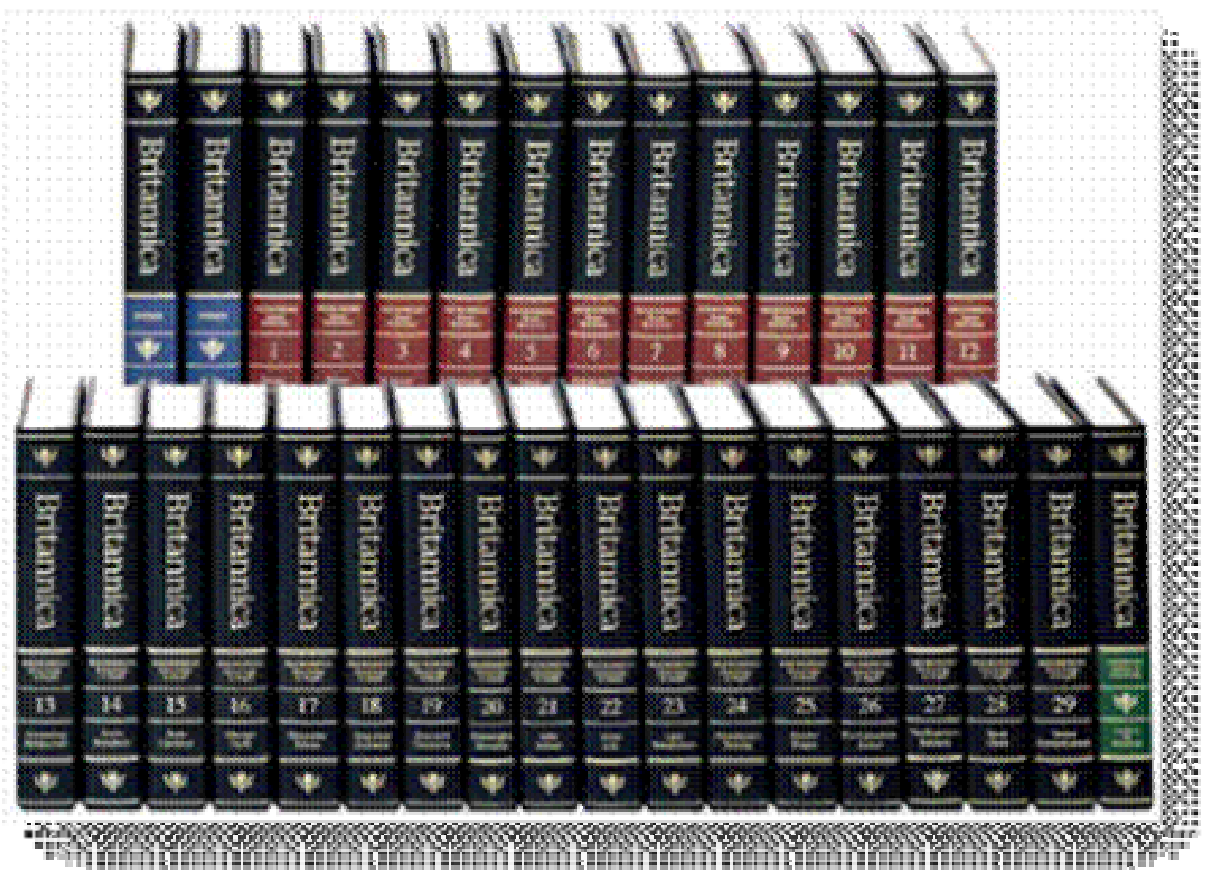


4. ¿Qué es hoy un diccionario?

Pues bien, si hablamos de esto en pasado, es porque hoy los diccionarios, esos objetos queya no están físicamente tan presentes en nuestra mesa de trabajo, han sido sustituidos por un conjunto de programas y de sitios web que cumplen las mismas finalidades que antes cumplían los distintos tipos de diccionarios.Ha pasado ya, de hecho, ese tiempo intermedio de los CD-ROM o los DVD-ROM (en la década de los 90), en los que a veces lo único que aportaba el nuevo soporte era una digitalización de lo existente en papel $^{7}$ (Fig. 21).Y ha pasado también el tiempo de los dispositivos dedicados exclusivamente a eso, aquellos pequeños ordenadores portátiles con materiales de referencia integrados y que suponían la posibilidad de consultar varios diccionarios (de distintos idiomas e incluso de distintas editoriales) en un mismo dispositivoelectrónico, ya que la función JUMP servía para saltar de uno a otro ${ }^{8}$ (Fig. 22).

Fig. 21 -Ediciones en CD-ROM de los diccionarios Clave, DRAE y Cambridge Compact.
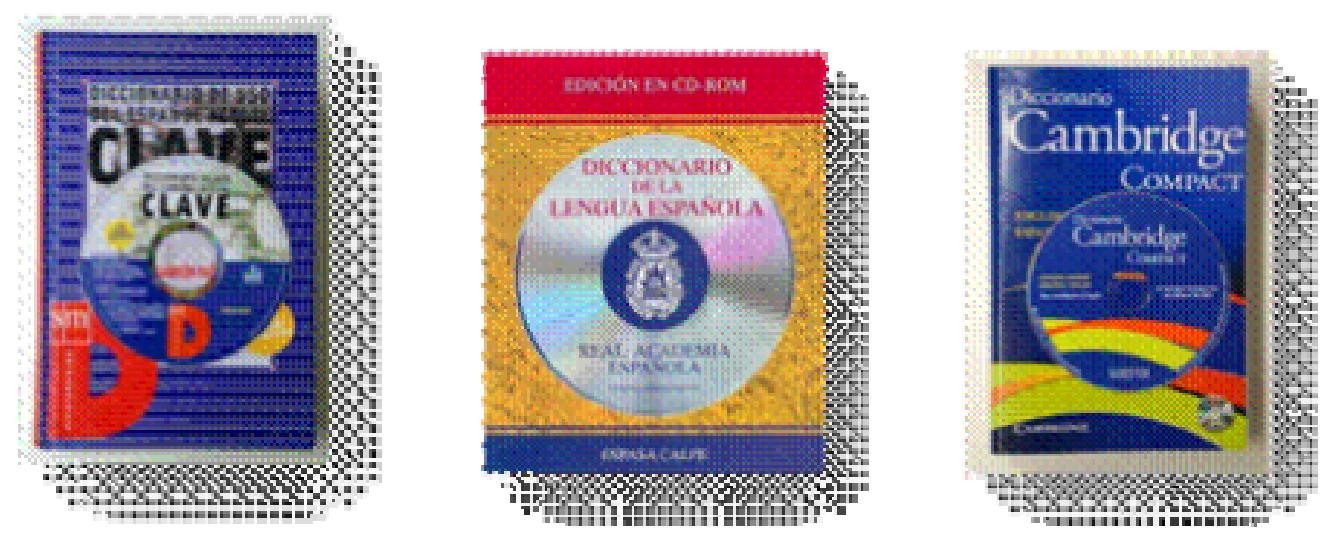

\footnotetext{
${ }^{7}$ Forgas et al., 2001

${ }^{8}$ Hoy, una versión simplificada y reducida de esos dispositivos es utilizada como gadget de márketing entre el target de gente joven, que, por ejemplo, prefiere viajar por toda Europa con un billeteinterRail y con las listas de equivalencias entre idiomas en un formato que le cabe en el bolsillo trasero del pantalón (algo que no siempre se podía decir de los llamados tradicionalmente diccionarios de bolsillo).
} 
Fig. 22 -Dispositivo dedicado Lexibook con el diccionario francés Robert; hubo una edición para el español con un diccionario Espasa Calpe en 1996. (Cf. Millán, 2011).

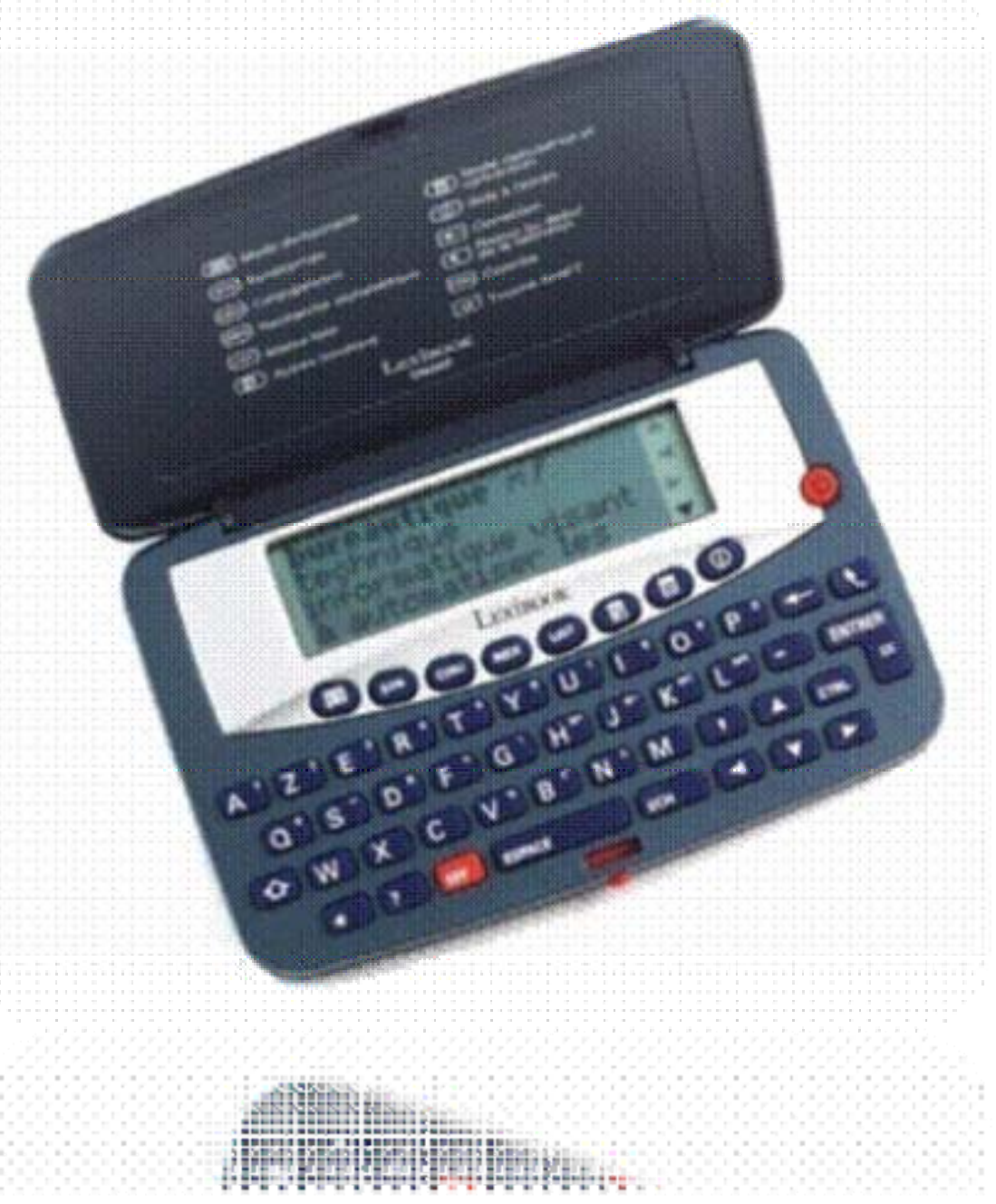

Estamos hablando de lexicografía digital (insistimos, no meramente digitalizada); estamos refiriéndonos a todos esos programas “intangibles” que hoy, desde nuestros ordenadores, nos resuelven las mismas dudas que antes nos resolvían un montón de diccionarios enpapel:

- Hoy, cualquier procesador de textos incluye entre sus funciones la comprobación ortográfica de los términos utilizados (y entre dichos términos incluye los nombres propios, esos nombres de personas, de obras culturales, o delugares geográficos que antes solo se podían encontrar en las obras enciclopédicas) (Fig. 23). 
- Hoy hay programas de lectura que permiten consultar el significado de una palabra con solo hacer clic sobre ella (Fig. 24).

- Hoy hay programas residentes en el ordenador que permiten consultar el significado de cualquier palabra en cualquier texto que aparezca en la web, un documento o el correo electrónico (DIXIO) (Fig. 25).

Fig. 23 -El corrector ortográfico de Word detecta que oy no es palabra en español, y sugiere alternativas.

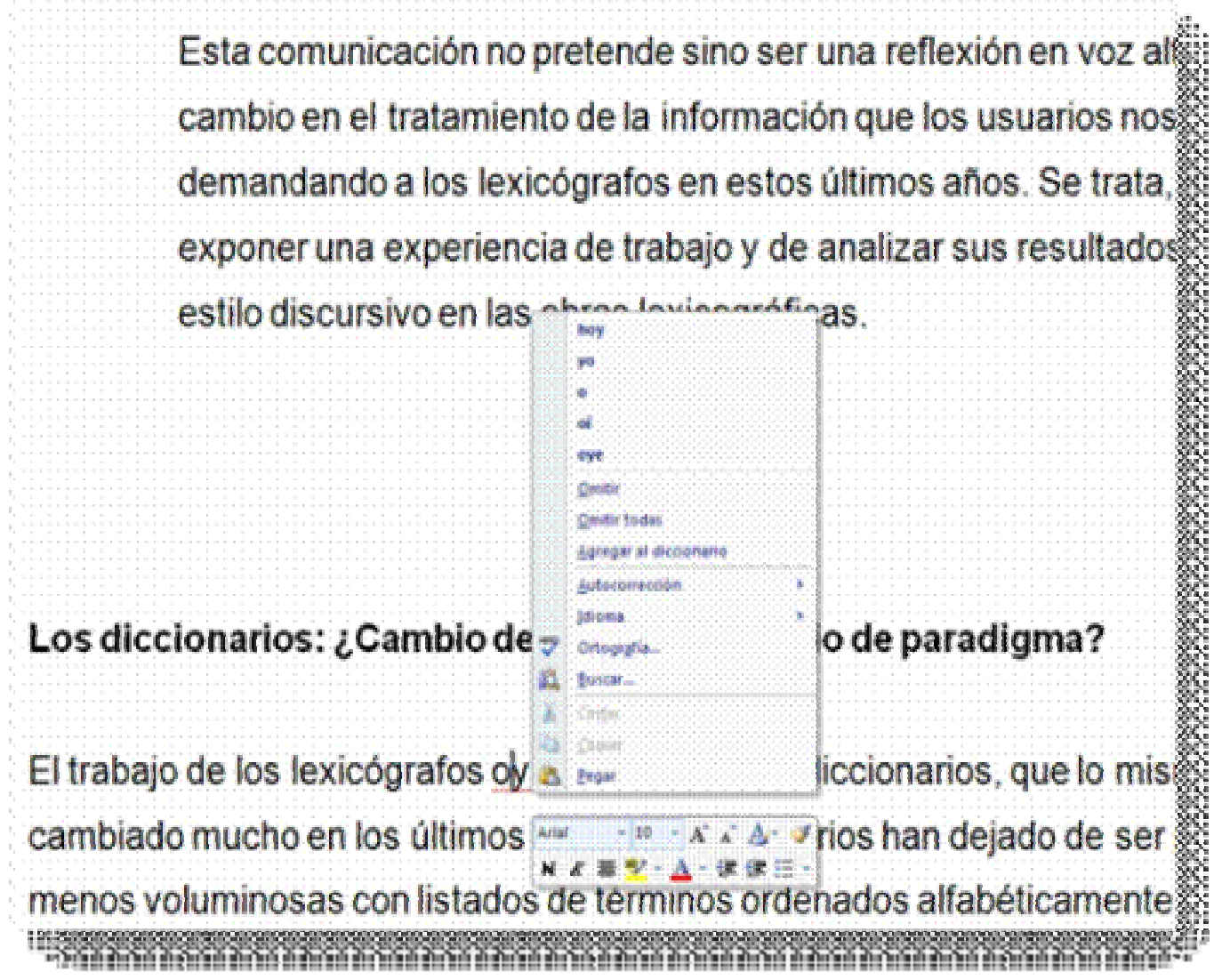


Fig. 24 -Diccionario incorporado en la aplicación Instapaper para iPhone (Cfr. Millán, 2011), y programa Dixio, que reconoce condujo como forma de conducir y presenta sus distintas acepciones, extraídas de un diccionario (Cf. Millán, 2011).

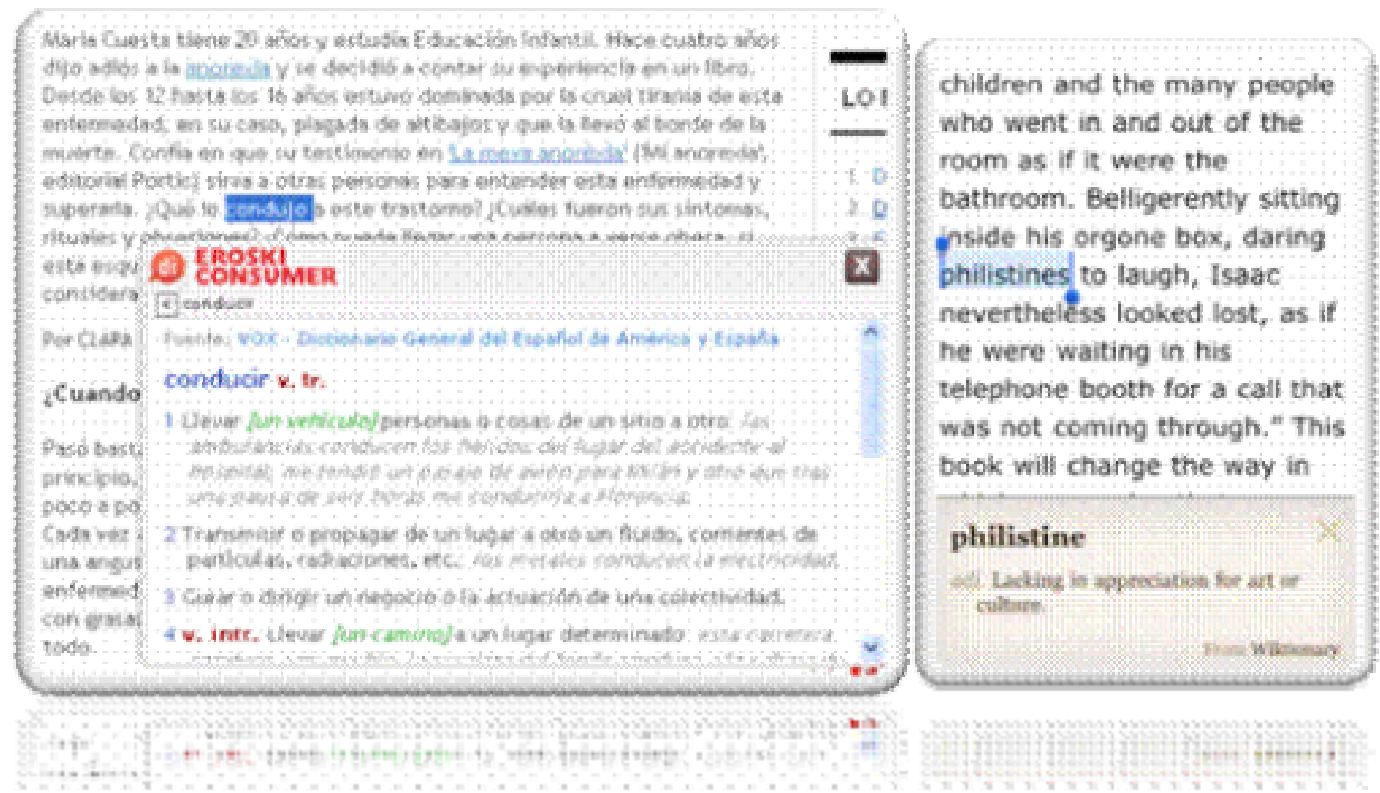

Fig. 25 -Palabra de un email traducida por Dixio (Cf. Millán, 2011).

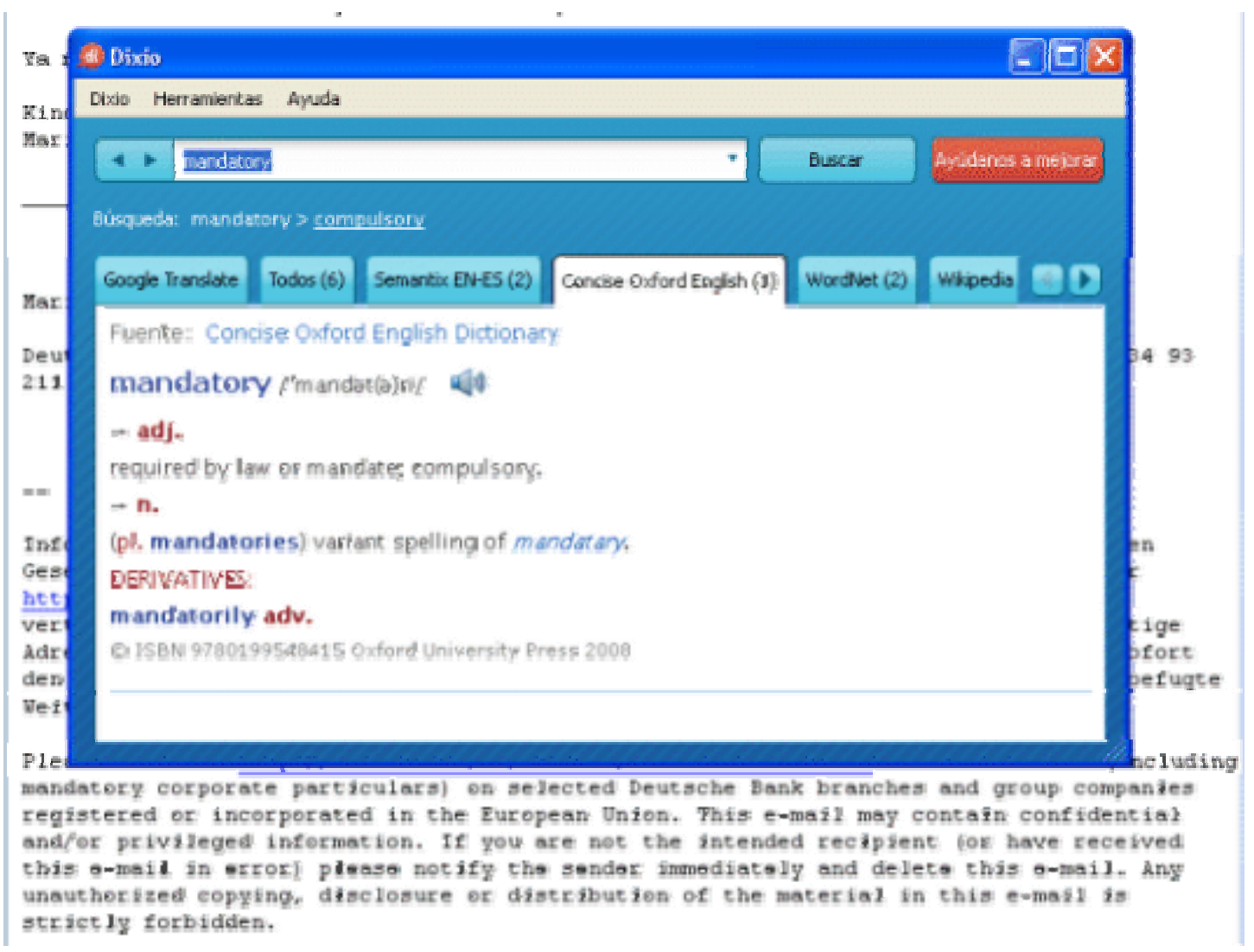


Y todas estas funciones se realizan sin necesidad de teclear la palabra buscada en su forma canónica en un caja de búsqueda: no hay que deducir que fui es ser o ir, y escribir después uno de los dos infinitivos, sino que pinchando (o tocando con el dedo) sobre esa palabra, la información se obtiene de forma inmediata.

¿Quiere esto decir que la entrada léxica desaparece como género discursivo? No, quiere decir que cambia. Radicalmente, además.

No hablaremos aquí de la información a la que accedemos cuando el diccionariocorre por debajo del texto, ya que en esos casos la única información que interesa al público no especialista es la definición, sino del diccionario que se consulta como tal, con una inicial caja de búsqueda (Fig. 26).

Fig. 26 -Tres ejemplos de diccionarios on line con caja de búsqueda.
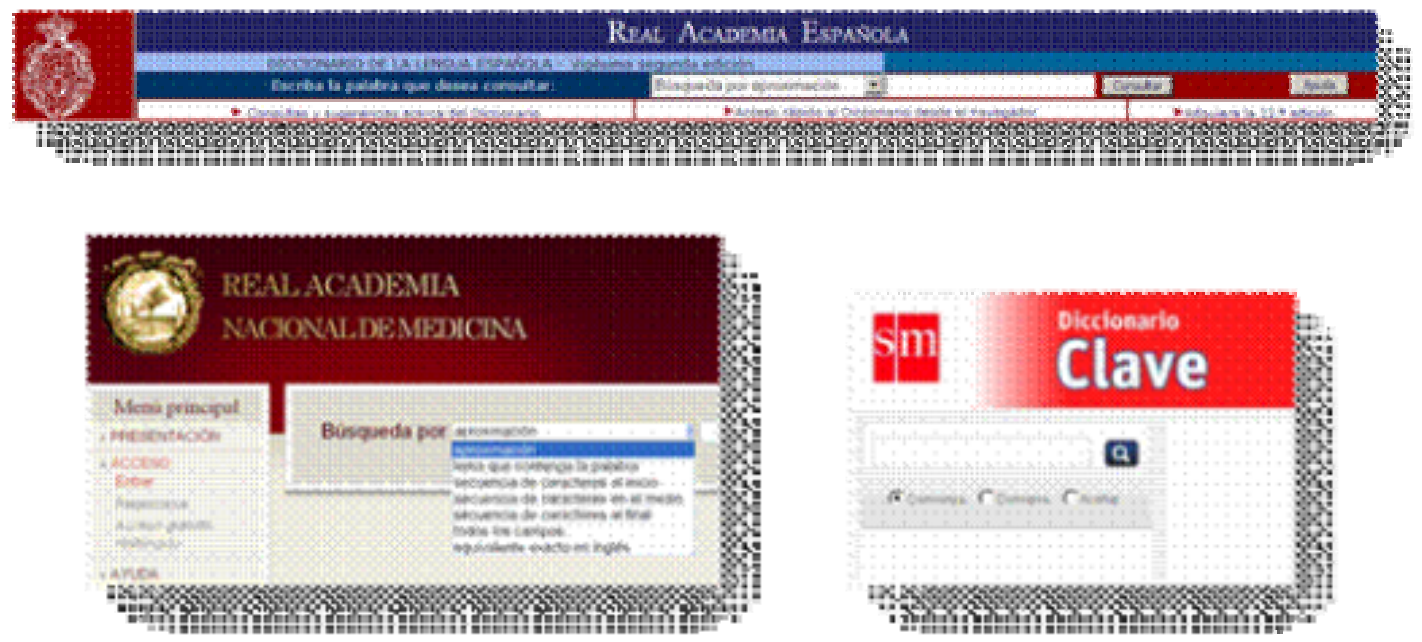

¿Qué esperamos de una entrada lexicográfica en digital?

- Que su concepción no venga constreñida por una limitación de espacio: que desaparezcan, pues, las abreviaturas (o, al menos, y dado que su desarrollo completo puede interferir en la lectura del texto, que sea información que pueda aparecer en un desplegable; Fig. 27). 
Fig. 27 -En los diccionarios de iniciación (en el sistema educativo español, dirigidos a usuarios de 8 años), el uso de abreviaturas no resulta didáctico.

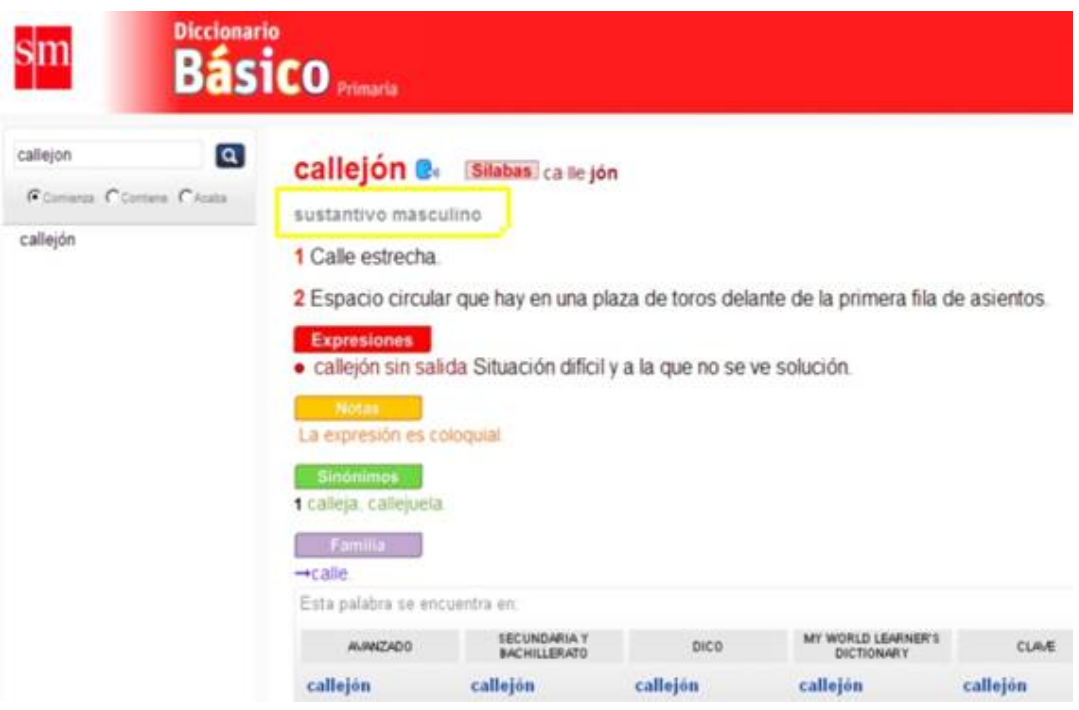

- Que la información se redacte con tanta redundancia como sea necesaria (Fig. 28).

- Que la información se complete con tantas ilustraciones, cuadros y cualquier otro tipo de información complementaria como se considere oportuno para una mejor comprensión del término consultado (Figs. 29a, 29b, 29c).

- Que lainformación sobre pronunciación esté ensoporte audio (Fig. 30).

Fig. 28a -El entorno digital permite que en el sustantivo derivado del verbo se desglosen las distintas acepciones, sin englobarlas bajo la tradicional fórmula “acción y efecto de...”.

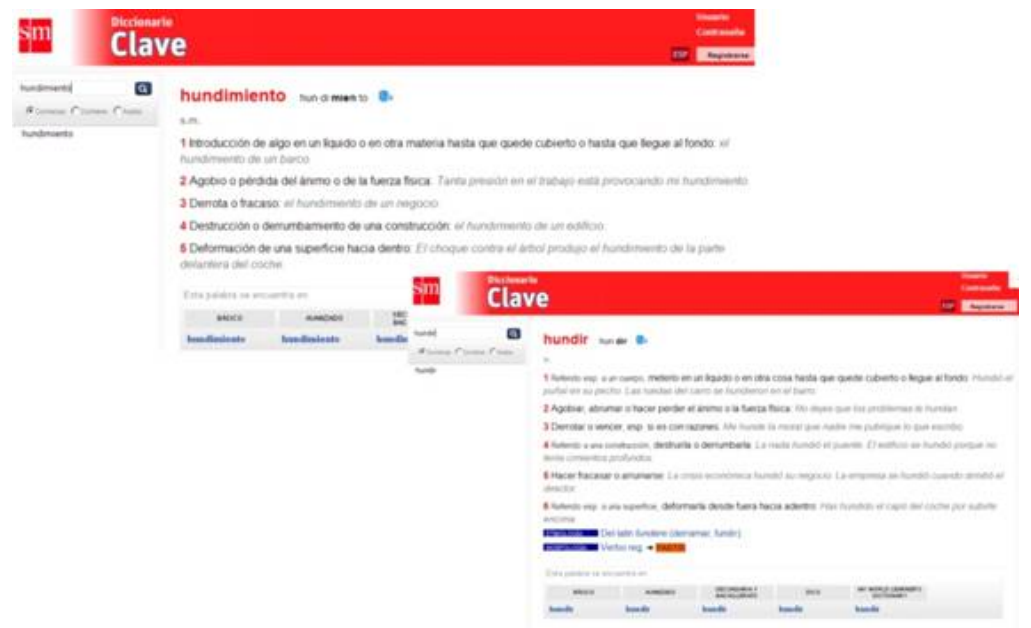


Fig. 29a -Inclusión de ilustraciones, y remisión a cuadros gramaticales o a guías de conversación.

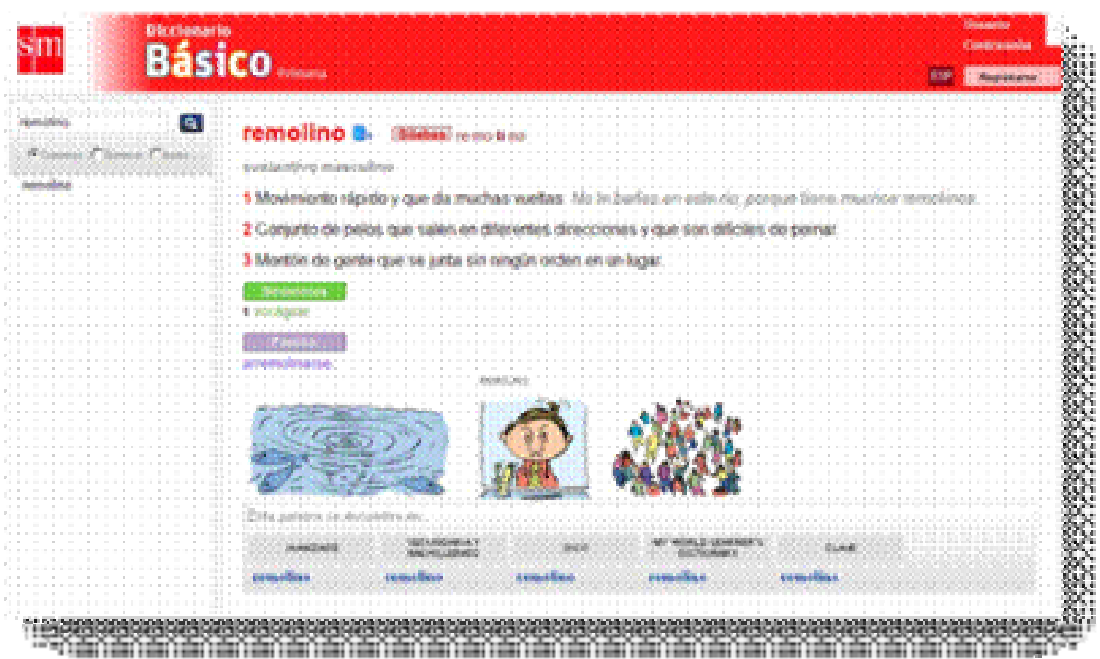

Fig. 29b -Inclusión de ilustraciones, y remisión a cuadros gramaticales o a guías de conversación.

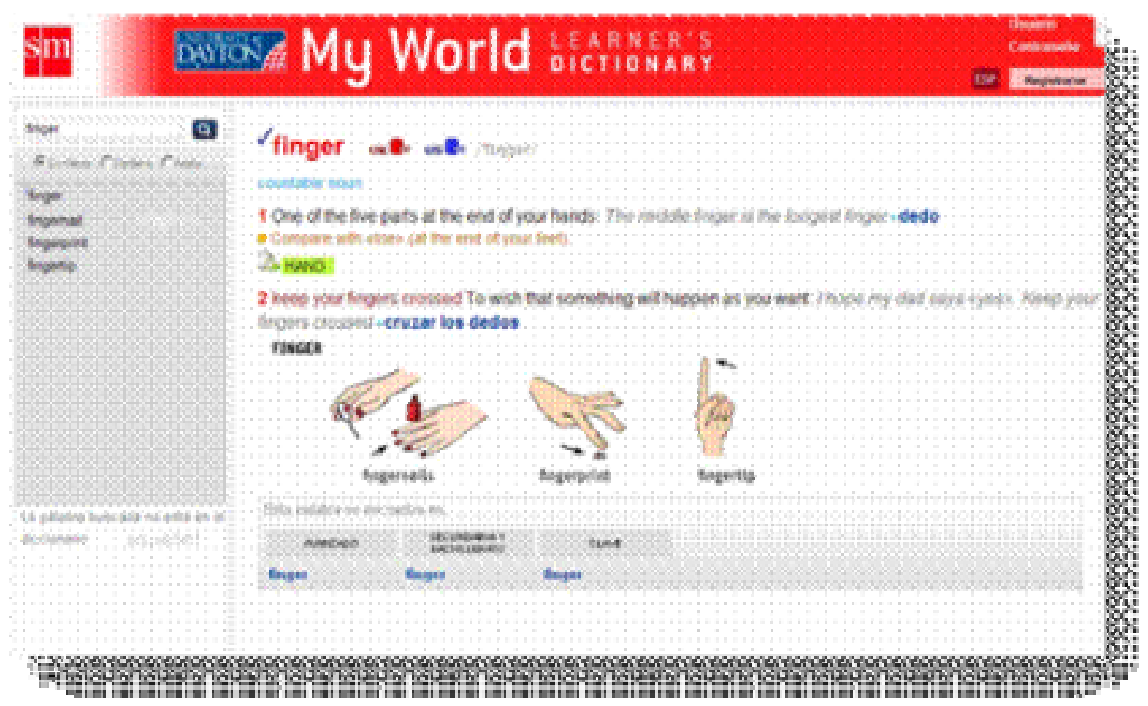


Fig. 29c -Inclusión de ilustraciones, y remisión a cuadros gramaticales o a guías de conversación.

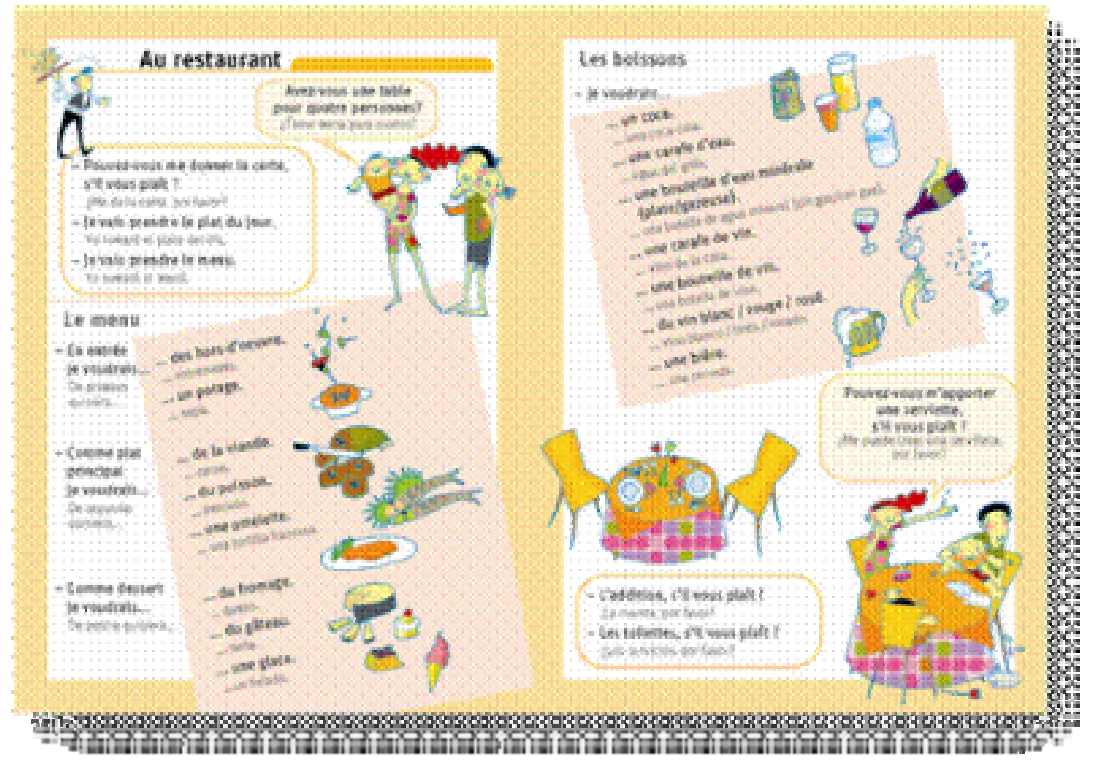

Fig. 30 -Audio de distintas variedades geográficas o regionales.

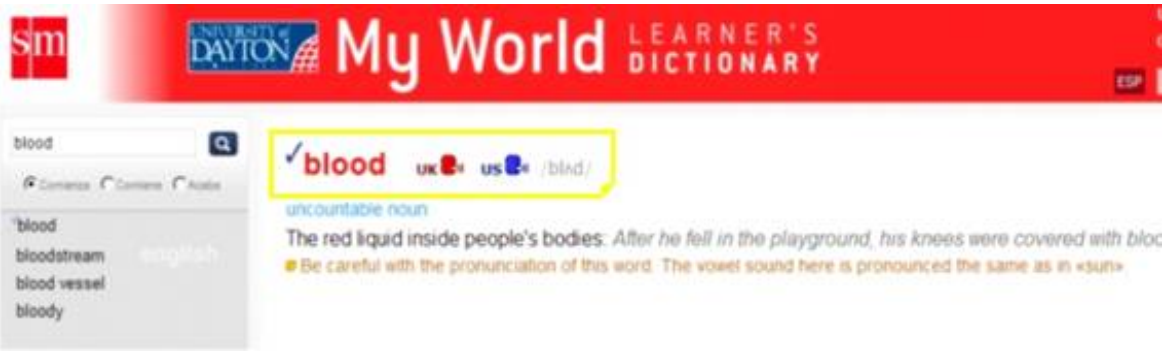

Y sin ceñirnos al género discursivo de la entrada, sino pasando ya a las funcionalidades de la búsqueda, creemos que hay a partir de ahora dos requisitos de calidad y eficacia exigibles siempre a la aplicación del procedimiento de la consulta:

- Aprovechamiento real del hipertexto dentro y fuera del propio diccionario ${ }^{9}$ : que tengamos la certeza de que si queremos adivinar el significado de conduje, el flexionador que corre debajo del programa nos va a llevar a conducir (Fig. 31); y que si estamos enun diccionario bilingüe, el programa nos ofrezca las posibilidades de encontrar palabras homógrafasen las dos partes del diccionario (Fig. 32).

\footnotetext{
${ }^{9}$ Es relevante, como señala Lladó (2009), que el hipertexto funcione tan bien en las obras de referenciay no haya triunfado, en cambio, para la creación literaria.
} 
- Enlaces con otros diccionarios, de otro tipo o en otros idiomas (Fig. 33).

- Ofrecimiento de la información en abierto para que el usuario busque según distintos criterios, acordes a sus distintas necesidades. Así, por ejemplo, mientras un profesor de Secundaria puede querer buscar todos los sustantivos femeninos que empiezan por $a$ - tónica y que, por tanto, llevan una nota morfológica sobre el uso de los determinantes masculinos el, un, algún, ningún, el profesor de ELE puede querer buscar todas los sustantivos masculinos del español que acaban en $-a$, o el profesor de francés puede querer buscar todos aquellos sustantivos que cambian el género gramatical en francés respecto del español. Con los resultados de las respectivas búsquedas, trabajarán con sus alumnos la corrección normativa: el aula frente a *este aula, el problema frente a *la problema, o la voiture frente a *le voiture.

Fig. 31 -El diccionario reconoce conduje como forma de conducir.

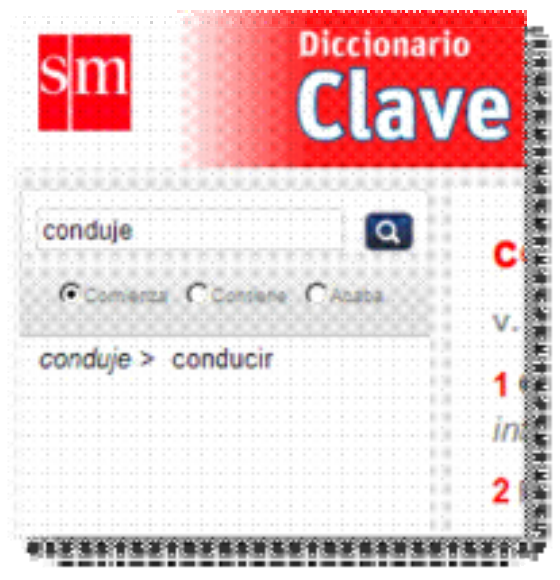


Fig. 32 -Asociación al diccionario correspondiente de palabras homógrafas en distintos idiomas.

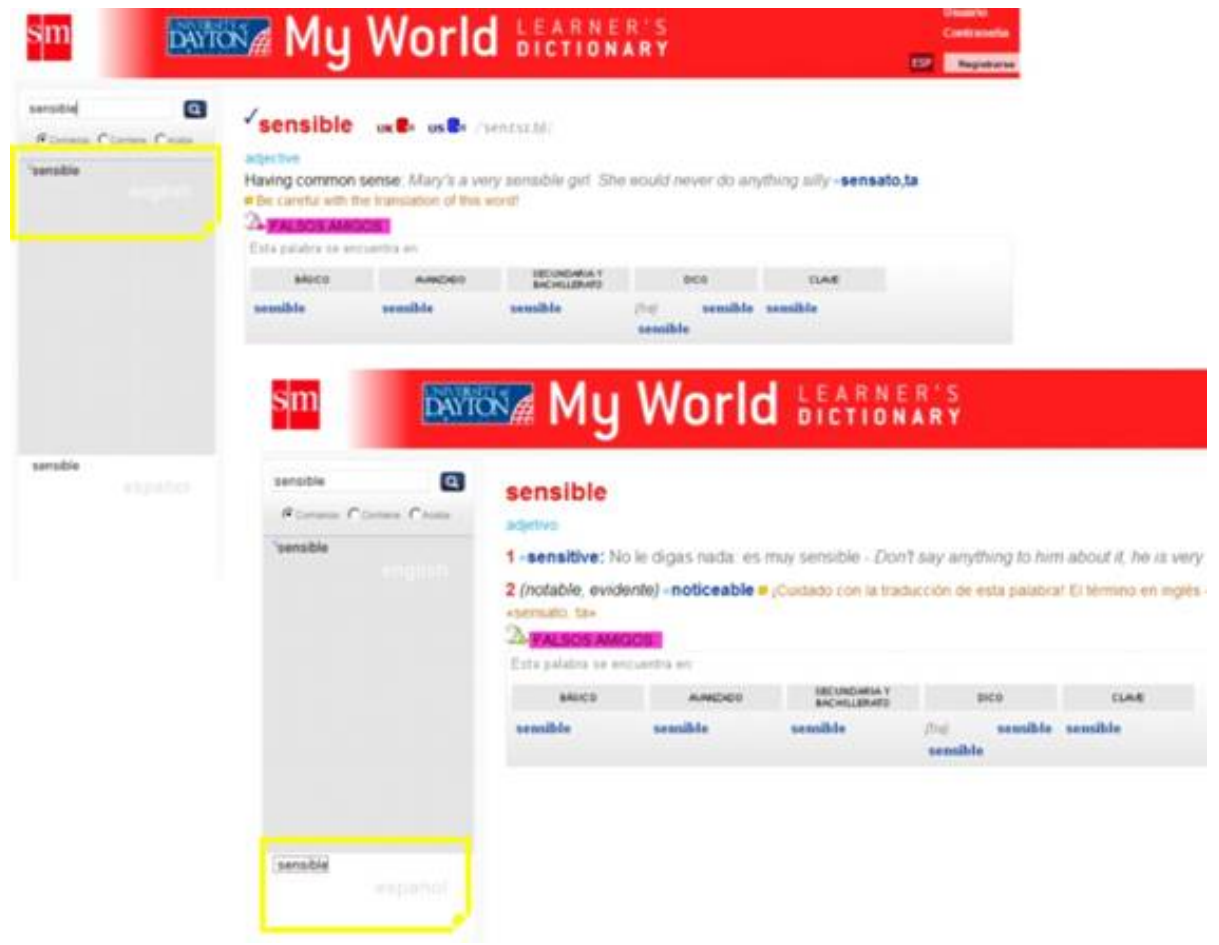

Fig. 33 -Remisión a otros diccionarios en los que la palabra también figura como lema.

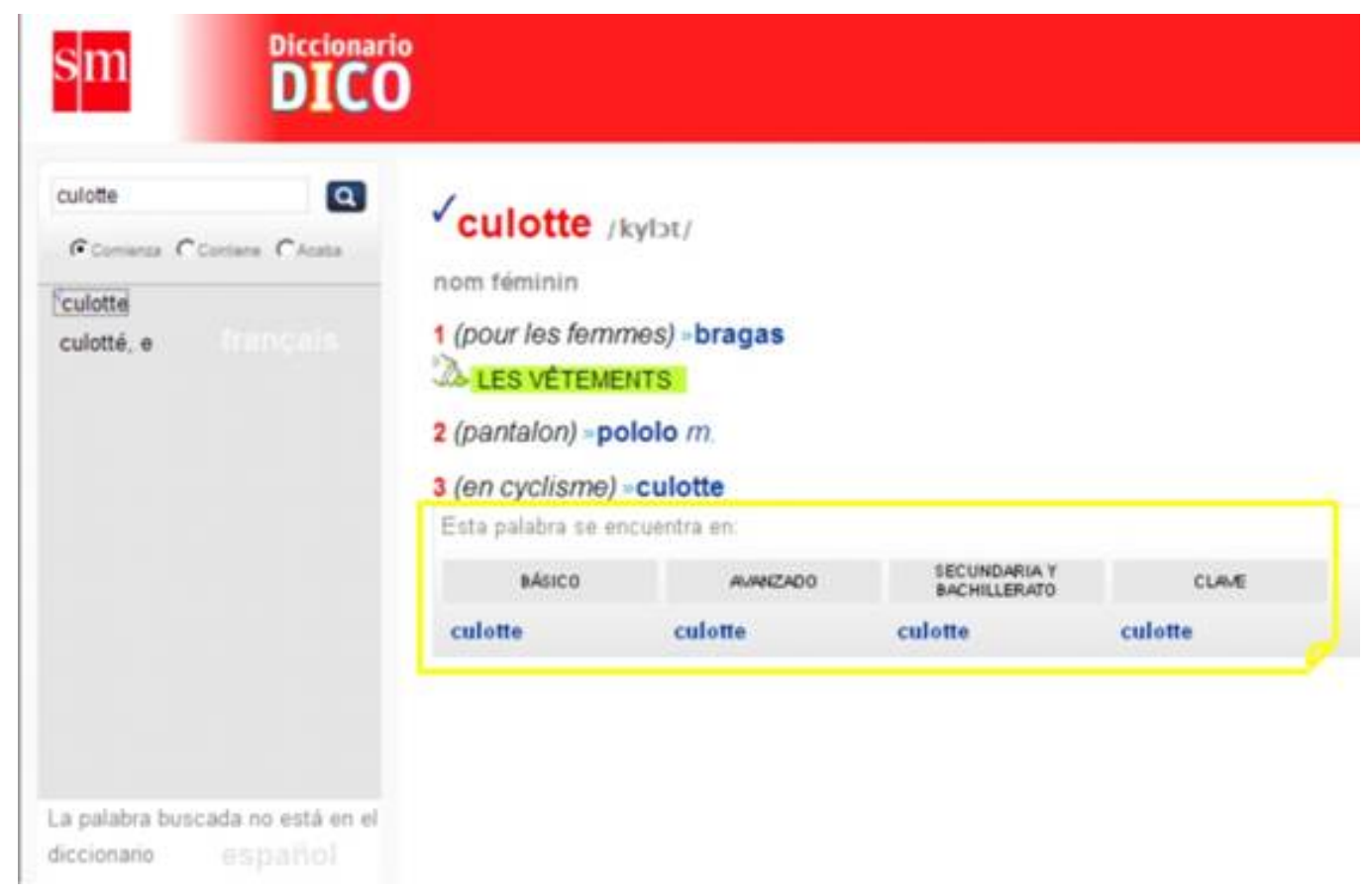




\section{Conclusión}

En resumen, y después de tan somera y superficial exposición, parece claro que el cambio de paradigma en el procedimiento de la consulta es real, ya está aquí. Es verdad que quedan varios años de convivencia entre el diccionario tradicional en papel y el nuevo tipo deobra de referencia (ese que corre por debajo de los software con que manejamos nuestros ordenadores). Pero lo que no ha cambiado desde que el ser humano es capaz de expresarse oralmente ha sido la capacidad de preguntarse sobre su lengua. Y mientras esa capacidad de dudar exista,las obras metalingüísticas de referencia tendrán sentido. ¿En qué género discursivo? En el que entre todos determinemos por el uso como el más eficaz comunicativamente.

\section{Bibliografía}

Corripio, Fernando (1971): Diccionario de ideas afines, Barcelona, Bruguera (2a ed.: Barcelona, Herder, 2007).

Ducrot, Oswald y Tzvetan Todorov (1983): Diccionario enciclopédico de las ciencias del lenguaje, México, Siglo XXI (23ª ed.: 2005)

Dyson, F. (1997). Imagined Worlds, Harvard University Press, 1997. (Mundos del futuro, Barcelona: Crítica, 1998).

Forgás, Esther, María Herrera y María Bargalló (2001): “Posibilidades y limitaciones de los diccionarios monolingües en CD-ROM en la clase de E/LE”, en Tecnologías de la Información y de las Comunicaciones en la Enseñanza de ELE. Actas de XII Congreso Internacional de ASELE, Valencia, Universidad Politécnica de Valencia, págs. 179-190. http://cvc.cervantes.es/ensenanza/biblioteca_ele/asele

Kuhn, T. S. The Structure of Scientific Revolutions, University of Chicago Press, 1962. (La estructura de las revoluciones científicas, México D.F.: Fondo de Cultura Económica, 1971). 
Lladó, Albert (2009): "La novela online: ¿Cambio de formato o cambio de paradigma?”, en el II Encuentro de Literatura Digital Interliteral, Jaén, 17 de septiembre de 2009. http://www.revistadeletras.net/la-novela-online\%C2\%BFcambio-de-formato-o-cambio-de-paradigma/

Maldonado, Concepción (dir.) (1999): Diccionario de sinónimos y antónimos, Madrid, SM (6 $6^{\mathrm{a}}$ ed.: 2012).

Maldonado, Concepción (dir.) (2002): Diccionario Eso y Bachillerato, Madrid, SM (4 ${ }^{\mathrm{a}}$ ed: 2012).

Maldonado, Concepción (dir.) (2008): Diccionario Cambridge Compact, Madrid, Cambridge University Press.

Maldonado, Concepción (dir.) (2012): http://smdiccionarios.com.

Millán, José Antonio (2011): “El diccionario oculto. Gloria y desaparición del diccionario en la era digital”, El País, 30 de julio. http://jamillan.com/librosybitios/gloriaydes.htm.

Millán, José Antonio (2012): “En la era de las obras tránsfugas. Aspectos culturales del abandono del papel”, El País, 7 de abril. http://jamillan.com/librosybitios/transf.htm

Real Academia Española y ASALE (2001): Diccionario de la lengua española, $22^{\mathrm{a}}$ ed. Madrid, Espasa. http://buscon.rae.es.

Rojo, Guillermo (2007): "Sobre la construcción de diccionarios basados en corpus”, en Tradumàtica. L'aplicació dels corpus lingüístics a la traducció, 7, Revista de Traducció i Tecnologies de la Informació i la Comunicació, http://webs2002.uab.es/tradumatica/revista/num7/articles/02/02art.htm.

Recibido: 12 junio 2013 Aceptado: 12 diciembre 2013 Revisado: 30 diciembre 2013

Publicado: 31 diciembre 2013 Actualizado: 17 enero 2013 